\title{
Orthopedic Operations in Blunt Traumatic Aortic Injury: Surgical Timing and Impact of Endovascular Aortic Repair
}

\author{
${ }^{1}$ Chih-Chen Kao, ${ }^{2}$ Shao-Wei Chen, ${ }^{3}$ Yun-Ching Huang, ${ }^{4}$ Yao-Kuang Huang, ${ }^{5}$ Feng-Chun Tsai, ${ }^{6}$ Pyng-Jing Lin
}

\begin{abstract}
Background: We reviewed the orthopedic intervention in patients with blunt aortic injury over a 17 -year period retrospectively, in order to evaluate the impact of aortic treatment options under the situation of concomitant orthopedic injuries.

Materials and methods: Information on demographics, mechanisms of trauma, injury scores, diagnostic tools, orthopedic procedures, aortic procedures, associated injuries, and hospital events was collected retrospectively from a tertiary trauma center. We applied $t$ test for continuous data, $\mathrm{X}^{2}$ test for categorical data, and nonparametrical tests for data not following normal distribution. Adjusted hazard ratio, 95\% confidence intervals, and $p$-values were derived from previously analyzed results.
\end{abstract}

Results: Between October 1995 and June 2012, there were $59(59 / 88,67 \%)$ patients with concomitant fractures among 88 patients, who have been proven to have blunt traumatic aortic injury (BTAl) in our institution. Among them, 31 underwent no orthopedic procedure (group I), and 28 received orthopedic fixation for functional restoration (group II). Among the two groups, group I had higher mortality rate despite an earlier documentation of aortic lesions at arrival.

For the patients in group II, 13 of them have received open aortic surgery and 6 of them have received endovascular aortic repair while the rest of the patients had minor BTAI, who were not indicated for invasive treatment. We compared demographic data, prognosis, and the timing of orthopedic procedures after aortic repair of patients with open aortic surgery $(n=13)$ and endovascular aortic repair $(n=6)$ to evaluate the impact of different aortic managements on these parameters. There was no difference between gender, age, injury severity, death, interval between injury to emergency room (ER), interval of trauma to orthopedic procedures, ER, intensive care unit and hospital stay. Nonetheless, patients treated with endovascular aortic repair tended to receive orthopedic procedure earlier after

${ }^{1}$ Resident, ${ }^{2,3,5,6}$ Attending Surgeon, ${ }^{4}$ Division Head

${ }^{1,4}$ Department of Cardiovascular and Thoracic Surgery, Chiayi Chang Gung Memorial Hospital and Chang Gung University Colledge of Medicine, Taoyuan, Taiwan

2,5,6 Department of Cardiovascular and Thoracic Surgery, Linkou Chang Gung Memorial Hospital and Chang Gung University Colledge of Medicine, Taoyuan, Taiwan

${ }^{3}$ Department of Urology, Chiayi Chang Gung Memorial Hospital and Chang Gung University, Colledge of Medicine, Taoyuan Taiwan

Corresponding Author: Yao-Kuang Huang, Division Head Department of Cardiovascular and Thoracic Surgery, Chiayi Chang Gung Memorial Hospital and Chang Gung University Colledge of Medicine, Taoyuan, Taiwan, Phone: +033186785 e-mail: huang137@icloud.com aortic intervention in comparison with those with open aortic surgery ( $2.2 \pm 2.6$ vs $6.9 \pm 5.7$ days, $p=0.03)$.

Conclusion: Patients with multiple traumas including BTAI had better outcome when they could be treated for aortic lesions operatively. Patients with BTAI who were treated with endovascular method tended to receive faster orthopedic corrections in comparison with patients who were treated with open aortic surgery.

Keywords: Blunt aortic injury, Endovascular, Fracture, Orthopedic, Trauma.

How to cite this article: Kao CC, Chen SW, Huang YC, Huang YK, Tsai FC, Lin PJ. Orthopedic Operations in Blunt Traumatic Aortic Injury: Surgical Timing and Impact of Endovascular Aortic Repair. Panam J Trauma Crit Care Emerg Surg 2018;7(1):38-46.

Source of support: This study was supported in part by the National Science Council of the Republic of China, Taiwan (Contract Nos. 103-2314-B-182A-073-MY2) and the ChangGung Memorial Hospital (Contract Nos. CMRPG6C0341 and CMRPG380841).

Conflict of interest: None

\section{RESUMEN}

Antecedentes: Hemos examinado la intervención ortopédica en pacientes con lesión aórtica romo durante un período de 17 años a posteriori, a fin de evaluar el impacto de las opciones de tratamiento de la aorta en la situación de lesiones ortopédicas concomitante.

Material y métodos: Información sobre demografía, mecanismos de trauma, lesiones partituras, instrumentos de diagnóstico, procedimientos ortopédicos, procedimientos de la aorta, lesiones asociadas, y el hospital de eventos fueron recogidos retrospectivamente a partir de un tercer centro de trauma. Se aplicó la prueba t para datos continuos, prueba de X2 para los datos categóricos y pruebas no paramétricas para datos no siguen una distribución normal. Hazard ratio ajustada, los intervalos de confianza del $95 \%$, y los valores de p fueron derivados de anteriores resultados analizados.

Resultados: Entre octubre de 1995 y junio de 2012, hubo 59 $(59 / 88,67 \%)$ de pacientes con fracturas concomitantes entre 88 pacientes que han demostrado tener blunt traumática lesión aórtica (BTAI) en nuestra institución. Entre ellos, 31 de ellos fueron sometidos a ningún procedimiento ortopédico (Grupo I) y 28 recibieron fijación ortopédica para la restauración funcional (Grupo II). Entre los dos grupos, el Grupo I tuvo la mayor tasa de mortalidad, a pesar de la documentación anterior de lesiones de la aorta en el momento de la llegada.

Para los pacientes en el grupo II, 13 de ellos han recibido cirugía aórtica abierta y cinco de ellos han recibido la reparación aórtica endovascular, mientras que el resto de los pacientes tenían BTAI menores que no estaban indicados para el tratamiento invasivo. Se compararon los datos demográficos, el 
pronóstico y la temporización de procedimientos ortopédicos tras una reparación aórtica de pacientes con cirugía aórtica abierta $(n=13)$ y la reparación aórtica endovascular $(n=6)$ para evaluar el impacto de diferentes gestión aórtica en estos parámetros. Los pacientes tratados con la reparación aórtica endovascular solían recibir procedimiento ortopédico después de la anterior intervención aórtica en comparación con aquellos con cirugía aórtica abierta ( $2.2 \pm 2.6$ días vs. 6,9 $\pm 5,7$ días, $p=0,03)$.

Keywords: Endovascular, Fractura, Lesión aórtica contusa, Ortopédico, Trauma.

\section{BACKGROUND}

Blunt traumatic aortic injury is the second leading cause of death from vehicle crashes. ${ }^{1}$ The majority of the mortality before arrival of hospital is attributable to massive bleeding from the injured aorta. With improvement of vehicle equipment and standards (e.g., safety belt, collision prevention), prehospital resuscitation, and traumatology and imaging techniques, more and more blunt aortic injuries can be detected by an experienced trauma center, and the surgical results have continually improved, especially with the innovative endovascular approach. ${ }^{2-6}$ Most patients with aortic trauma sustained high-energy during motor vehicle collisions or crushing, and often have additional associated injuries, such as fractures. However, the distribution, severity of the bone fractures, and the timing of fixation in dealing with patients with blunt aortic trauma have seldom been discussed. ${ }^{7,8}$

In this study, we reviewed 17 years of experience in treating orthopedic problems in patients with BTAI.

\section{MATERIALS AND METHODS}

\section{Patients}

This retrospective study was conducted after obtaining the approval of our Institutional Review Board. Patients with typical aortic lesion after blunt trauma between October 1995 and June 2012 were enrolled. The following information was collected: age, gender, mechanism of trauma, presenting symptoms, associated injuries, initial vital signs and lab tests, diagnostic tools, Glasgow Coma Scale, Injury Severity Score (ISS), Revised Trauma Score (RTS), survival probability determined by using the Trauma and Injury Severity Score (TRISS), time for diagnosis and surgery, aortic surgical procedures (nonoperative, open surgery, and endovascular aortic repair), degree of aortic injury, fracture location, fracture severity, fracture management, hospital events, and final outcome.

Therapeutic strategy: open aortic surgery and endovascular aortic repair.

\section{Open Aortic Surgery}

Either traditional open surgery or endovascular interventions were attempted once the blunt aortic injury was determined, except for patients at extremely high risk and only minor aortic lesions. We did not apply permissive hypotension to those patients with traumatic aortic injury, but kept their systolic pressure less than $120 \mathrm{~mm}$ $\mathrm{Hg}$ in the ICU until definitive aortic repair. Most open surgeries for aortic lesions were scheduled at 3 to 7 days after major trauma, if there was no free rupture and no involvement of the ascending aorta. Traditional open surgery was done with a double-lumen endotracheal tube under general anesthesia. Left posterolateral thoracotomy was the preferred incision and the repair was carried out under full cardiopulmonary bypass and deep hypothermic circulatory arrest in most cases. All patients, including those who received nonoperative treatment, were admitted to the ICU for at least 48 hours to monitor late bleeding, rupture, ventricular arrhythmia, and deterioration of concomitant trauma.

\section{Endovascular Aortic Repair}

Endovascular repair has been available at our institution since 2006. All patients had preoperative images prepared, consisting of a contrast computed tomography (CT) angiography of the chest and abdomen. Evaluation for suitability of endovascular aortic repair included aortic morphology, aortic arch involvement, size of the thoracic/abdominal aorta, and iliac arteries. All procedures were performed in the operating room, typically through open femoral arteries.

\section{Orthopedic Procedure}

Patients with unstable hemodynamics, especially with pelvic fractures or complex open fractures received external fixation and open reduction with internal fixation emergently. However, most of the orthopedic procedures were performed on the elective schedule after aortic lesion has been fixed or stabilized. In extremely destructed limb, amputation is an acceptable treatment modality for reducing infection and saving life. Cast, plastic splint, and tendon repair were not included in orthopedic fixation of the fracture in this study.

\section{Statistical Analysis}

All data were entered into an Excel spreadsheet (Excel 2007, Microsoft Inc. USA) and analyzed using STATA software, version 8.0 (Stata Corporation, College Station, TX). Categorical variables were reported as frequencies, and all continuous variables were calculated as mean \pm standard deviation. Continuous data were compared using a one-sample $t$ test for paired data and a two-sample $t$ test for unpaired data, when appropriate. Categorical data were compared using the $\mathrm{X}^{2}$ test. Nonparametrical tests were applied to data not following a normal 
distribution. A significance level of 5\% was applied when comparing differences. Cox regression analysis was used to compare different influences on mortality among the study groups, adjusting for sex, age, TRISS, aortic injury type, fracture detail, and orthopedic procedures. The adjusted variables were selected according to their clinical relevance in patients with multisystem trauma and previously published literature. Adjusted hazard ratio, 95\% confidence intervals, and p-values were derived.

\section{RESULTS}

Between October 1995 and June 2012, there were 88 patients admitted to a tertiary trauma center, who were documented as having blunt aortic injury and 59 (59/88,67\%) of them have been documented with fracture. Table 1 shows the characteristics of the 59 patients including gender, age, injury severity, timing of arrival, timing of aortic lesion proven, presenting symptoms, arriving biochemistry, aortic management, fracture management, and followup interval. There were 48 males and 11 females, with a mean age of $40.5 \pm 18.5$ (range 15-79). The time interval between trauma occurrence and arrival at the ER was $6.3 \pm$ 16.4 hours, with the aortic injury disclosed in $6.6 \pm$ 17.5 hours after arrival at the ER. Although most of the

Table 1: Summary statistics $(n=59)$

\begin{tabular}{|c|c|}
\hline Variables & $\%($ Mean $\pm S D)$ \\
\hline Gender: Male & $48(81.4 \%)$ \\
\hline Age & $40.5 \pm 18.5$ \\
\hline ISS & $30.2 \pm 9.8$ \\
\hline RTS & $6.8 \pm 1.5$ \\
\hline TRISS & $0.8 \pm 0.3$ \\
\hline \multicolumn{2}{|l|}{$\begin{array}{l}\text { Aortic lesion proven later than orthopedic } \\
\text { Operations }\end{array}$} \\
\hline Yes & $4(6.8 \%)$ \\
\hline No & $55(93.2 \%)$ \\
\hline Scapula fracture & $2(3.4 \%)$ \\
\hline \multicolumn{2}{|l|}{ Fracture management } \\
\hline Conservative (group I) & $31(52.5 \%)$ \\
\hline Fixation by orthopedic surgeon (group II) & $28(47.5 \%)$ \\
\hline \multicolumn{2}{|l|}{ Aortic management } \\
\hline Open surgery & $29(49.2 \%)$ \\
\hline Endovascular aortic repair & $14(23.7 \%)$ \\
\hline Conservative management & $16(27.1 \%)$ \\
\hline Median of follow-up days & 685 days \\
\hline \multicolumn{2}{|c|}{ Timing of arrival and aortic lesions proven (hours) } \\
\hline Trauma to ER & $6.3 \pm 16.4$ \\
\hline ER to diagnosis & $6.6 \pm 17.5$ \\
\hline \multicolumn{2}{|l|}{ Presentation symptoms/signs of aortic injury } \\
\hline Chest and back pain & $13(22.0)$ \\
\hline Shock & $20(33.9)$ \\
\hline No related symptoms & $26(44.1)$ \\
\hline \multicolumn{2}{|l|}{ Lab at arrival } \\
\hline Hematoglobin (g/dL) & $11.8 \pm 2.2$ \\
\hline Creatinine (ng/dL) & $1.2 \pm 1.5$ \\
\hline
\end{tabular}

patients presented with shock $(13 / 59,22 \%)$ and chest pain (20/59, 33.9\%), 26 (44.1\%) patients showed no sign of aortic injury. Their ISS, RTS, and TRISS scores were $30.2 \pm 9.8$, $6.8 \pm 1.5$ and $0.8 \pm 0.3$ respectively. The median follow-up time was 685 days and the in-hospital mortality was $18.6 \%$.

Aortic intervention, including open surgery and endovascular repair, were arranged once the diagnosis of blunt aortic injury was established, except for the 16 patients with extremely high risk and/or only minor aortic lesions $(16 / 59,27.1 \%)$. There were 29 patients $(29 / 59,49.2 \%)$ with BTAI who received open surgery, and 14 patients $(14 / 59,23.7 \%)$ with BTAI who received endovascular aortic repair, for aortic lesion. The fractures were treated conservatively in 31 patients (group I) and were treated operatively in 28 patients (group II). Notably, there were four patients in group II $(4 / 28,14.3 \%)$ who received orthopedic fixation before detection of the aortic trauma. The comparison between group I and group II is shown in Table 2. The two groups did not differ in gender, age, ISS, RTS, TRISS, trauma to ER time, hemoglobin on arrival, serum creatinine on arrival, and aortic management. Group I (conservative management of fracture) had higher mortality, but shorter time from arrival to diagnosis of aortic lesion ( $5.7 \pm 17.7$ vs $7.6 \pm 17.5$ hours $)$.

\section{Orthopedic Pathology and Procedures}

There were 28 patients (group II) with aortic trauma who received operation for the fractures. There were seven

Table 2: Patients with fractures in different treatment: group I (conservative treatment of the fracture) and group II (receiving fixation for fractures)

\begin{tabular}{|c|c|c|c|}
\hline Variables & $\begin{array}{l}\text { Group I } \\
(n=31)\end{array}$ & $\begin{array}{l}\text { Group II } \\
(n=28)\end{array}$ & p-value \\
\hline Gender: Male & $26(44.1)$ & $22(37.3)$ & 0.60 \\
\hline Age & $43.6 \pm 17.9$ & $37.0 \pm 18.8$ & 0.13 \\
\hline ISS & $30.7 \pm 11.8$ & $29.5 \pm 7.1$ & 0.68 \\
\hline RTS & $6.8 \pm 1.7$ & $6.9 \pm 1.2$ & 0.66 \\
\hline TRISS & $0.8 \pm 0.3$ & $0.9 \pm 0.2$ & 0.28 \\
\hline Death & 10 & 1 & 0.004 \\
\hline \multicolumn{4}{|l|}{ Timing and arriving status } \\
\hline Trauma to ER (hours) & $8.8 \pm 22.1$ & $3.5 \pm 4.5$ & 0.42 \\
\hline $\begin{array}{l}\text { Diagnosis of aortic lesion } \\
\text { (hours) }\end{array}$ & $5.7 \pm 17.7$ & $7.6 \pm 17.5$ & 0.02 \\
\hline Presentation symptoms/signs & & & 0.02 \\
\hline Chest and back pain & 11 & 2 & \\
\hline Shock & 10 & 10 & \\
\hline Others & 10 & 16 & \\
\hline Aortic surgery & & & 0.51 \\
\hline Conservative & 9 & 7 & \\
\hline Traditional open & 15 & 14 & \\
\hline Endovascular & 7 & 7 & \\
\hline \multicolumn{4}{|l|}{$L a b$} \\
\hline Hematoglobin (g/dL) & $12.2 \pm 2.1$ & $11.5 \pm 2.4$ & 0.24 \\
\hline Creatinine (ng/dL) & $1.4 \pm 2.1$ & $1.0 \pm 0.3$ & 0.70 \\
\hline
\end{tabular}


pelvic fractures (with/without extremity fractures), three spinal fractures, one flail rib fracture, four complex extremity fractures (i.e., more than two different extremity fractures), and 13 single extremity fractures. The fracture details, surgical procedures, and other information (e.g., associated injury or aortic management) are summarized in Table 3. Only the patients with unstable hemodynamics, especially those with pelvic fractures or complex open fractures received external fixation and open reduction with internal fixation emergently. Most orthopedic procedures were performed as open/close reduction, with internal fixation on the elective schedule after the aortic lesion was stabilized. One above-knee amputation was performed as life-saving management.

Table 3: Fracture requiring orthopedic intervention in patients with blunt aortic trauma $(n=28)$

\begin{tabular}{|c|c|c|c|}
\hline $\begin{array}{l}\text { Fracture } \\
\text { category Fracture detail }\end{array}$ & Surgical procedure & $\begin{array}{l}\text { Orthopedic } \\
\text { procedure } \\
\text { before aortic } \\
\text { lesion proven } \\
(n=4)\end{array}$ & Other information \\
\hline
\end{tabular}

category Fra

$1 \quad$ Pelvic and left femoral shaft (AO/OTA 32-B1)

2 Acetabulum fracture (Thompson and Epstein Classification type V)

Sciatic nerve injury

3 Pelvic fracture

Right closed TF fracture (The Müller AO

Classification 42-B2)

$4 \quad$ Stable pelvic fracture

Left femoral shaft open fracture (The Müller AO Classification 32 C3) 2 left tibial fracture (The Müller AO Classification 42-B1)

5 Pelvic lesion: left acetabulum fracture Right ulnar shaft fracture

Unstable pelvic with acetabular fracture (Thompson and Epstein Classification type V)

TL spine compression fracture

$7 \quad$ Left pelvic fracture (iliac ring fracture) Left radial and ulnar fracture (The Müller AO Classification 21-A3)
Simultaneous ORIF for pelvis and left femorus

Fixation with cancellous screws (early $Y$ total care)

TF ORIF then pelvic ORIF 3 days later

External fixation of the femoral shaft $Y$ fracture.

ORIF for left tibial fracture (interlocking snail)

Multiple debridement

Conservative treatment for pelvic fracture

Posterior approach for acetabular fracture, ORIF with posterior column screw and plate

ORIF for right ulnar shaft fracture

(5 days after fixation of pelvic fracture)

Close reduction and external fixation of the pelvic fracture

Acetabular reconstruction (5 days after

CREF of pelvic fracture)

Posterior instrumentation, T12-L2, vertebroplasty of L1 (5 days after CREF of pelvic fracture)

Conservative treatment for pelvic fracture

ORIF of radius and ulna

\section{Spine and rib $(n=4)$}

1 T10-11 disk herniation with spinal process Laminectomy fracture

$2 \quad$ Unstable T7-T8 fracture

3 T3-5 fracture dislocation

$4 \quad$ Filial rib fracture

Complex extremity $(n=4)$

$1 \quad$ Left shoulder dislocation, left closed radius fracture (The Müller AO Classification 21-

A2) and right femoral shaft fracture (32-A2)

2 Right-closed femoral neck fracture(31-B3); right-closed tibial fracture(42-B1); left radius fracture $(21-\mathrm{A} 2)$
Fixation

Fixation 2 weeks after injury

Rib reduction by miniplate

Hemopericardium with cardiac rupture

One-stage

Sciatic nerve injury One-stage

One-stage

Conservative treatment of the pelvic fracture

One-stage for pelvic lesion

No aortic surgery, staged operation for pelvic lesion

Debridement of hip osteomyelitis 11 days after ORIF, Conservative for pelvic lesion

No aortic surgery

CREF for radius fracture, ORIF for $\quad Y$ femoral shaft fracture

Before aortic injury diagnosed

(Cont'd...) 
(Cont'd...)

\begin{tabular}{|c|c|c|c|c|}
\hline $\begin{array}{l}\text { Fracture } \\
\text { category }\end{array}$ & Fracture detail & Surgical procedure & $\begin{array}{l}\text { Orthopedic } \\
\text { procedure } \\
\text { before aortic } \\
\text { lesion proven } \\
(n=4)\end{array}$ & Other information \\
\hline 3 & $\begin{array}{l}\text { Left femoral neck fracture (32-B2) } \\
\text { Left Galeazzi fracture } \\
\text { Left 4th and 5th metacarpal fracture }\end{array}$ & ORIF & & \\
\hline 4 & $\begin{array}{l}\text { Right proximal T-F comminuted open } \\
\text { fracture (41-C2) } \\
\text { Left distal femoral shaft open fracture } \\
\text { Left patella fracture (33-C3) } \\
\text { Left } 4 \text { th and } 5 \text { th metacarpal fracture } \\
\text { Scapula fracture }\end{array}$ & $\begin{array}{l}\text { Right above-knee amputation and left } \\
\text { above-knee amputation }\end{array}$ & & $\begin{array}{l}\text { No aortic surgery; } \\
\text { Mortality }\end{array}$ \\
\hline \multicolumn{5}{|c|}{ Simple extremity or single extremity fracture $(n=13)$} \\
\hline 1 & Right femoral neck fracture (31-B2) & CRIF & & No aortic surgery \\
\hline 2 & Right TF fracture (42-A2) & CRIF & & \\
\hline 3 & Right TF open fracture (42-A2) & ORIF & & No aortic surgery \\
\hline 4 & $\begin{array}{l}\text { Left olecranon fracture }(21-\mathrm{B} 1) \text { and } \\
\text { multiple ribs fracture }\end{array}$ & ORIF & & \\
\hline 5 & Right femoral shaft fracture $(32-\mathrm{A} 1)$ & ORIF & & \\
\hline 6 & $\begin{array}{l}\text { Right femoral subtrochanteric fracture } \\
(31-\mathrm{A} 1)\end{array}$ & CRIF & & \\
\hline 7 & $\begin{array}{l}\text { Left olecranon fracture }(21-\mathrm{B} 1) \text { and } \\
\text { zygomatic fracture }\end{array}$ & ORIF & & No aortic surgery \\
\hline 8 & Left femoral shaft fracture (32-A1) & ORIF & & No aortic surgery \\
\hline 9 & Right femoral shaft fracture (32-A2) & $\begin{array}{l}\text { Closed static interlocking nail } 12 \mathrm{~mm} \\
\times 40 \text { fixation }\end{array}$ & & \\
\hline 10 & $\begin{array}{l}\text { Right femoral shaft (32-A1) and femoral } \\
\text { neck fracture (32-B1) }\end{array}$ & Close reduction and internal fixation & & \\
\hline 11 & Left tibial open fracture (42-A1) & Dynamic compression plate & Y & $\begin{array}{l}\text { Before aortic injury } \\
\text { diagnosed }\end{array}$ \\
\hline 12 & Left femoral shaft fracture $(32-\mathrm{A} 1)$ & $\begin{array}{l}\text { ORIF with intermaleolar fixation (IM } \\
\text { fixation) }\end{array}$ & & \\
\hline 13 & Right femoral shaft open fracture (32-A1) & $\begin{array}{l}\text { External fixation of right femur fracture, } \\
\text { ORIF } 2 \text { weeks later }\end{array}$ & & \\
\hline
\end{tabular}

AO/OTO: The AO foundation and orthopaedic trauma association; TF: Tibiofibular; TL: Thoracolumbar; ORIF: Open reduction and internal fixation; CREF: Close reduction and external fixation

Of the seven patients with pelvic fractures, four received simultaneous fixation of fractures of the pelvis and lower extremities, one patient received external fixation of the pelvis emergently and then reconstruction of the pelvis later (staged operation), and the three remaining patients underwent operation only on the extremity fractures, while conservative treatment for the pelvic fractures was administered.

It is worth pointing out that the aortic injuries were disclosed only after the orthopedic procedures were completed in four of the patients $(4 / 28,14.3 \%)$. One patient with pelvic fracture and another with complex extremity fractures had their aortic lesions detected after discharge. The third case was a 15 -year-old female with external fixation of an open femoral shaft fracture. Her aortic lesion was detected because of profound shock in the ICU. That patient received endovascular repair of thoracic aorta with carotid-to-carotid bypass and subsequent multiple orthopedic reconstructions (Figs 1 and 2).
The fourth patient was a patient with type II open tibial fracture, who received dynamic compression plate. The postoperative plain chest $\mathrm{X}$-ray showed a more extensive widening of the mediastinum compared with the pre-op one, and the aortic lesion was proven in contrast chest CT.

\section{Orthopedic Procedures: Timing and Impact of Different Aortic Interventions}

Among the 28 patients who have received orthopedic procedure with coexisting aortic injury, four of them were found to have aortic lesions after orthopedic procedures, seven received nonoperative management for blunt aortic injury, 13 received traditional open aortic surgery, and six received endovascular aortic repair. We compared the patients with open aortic surgery $(n=13)$ with those with endovascular aortic repair $(n=6)$ to evaluate the impact of different aortic managements (Table 4). There were no difference found for gender, age, injury severity, 

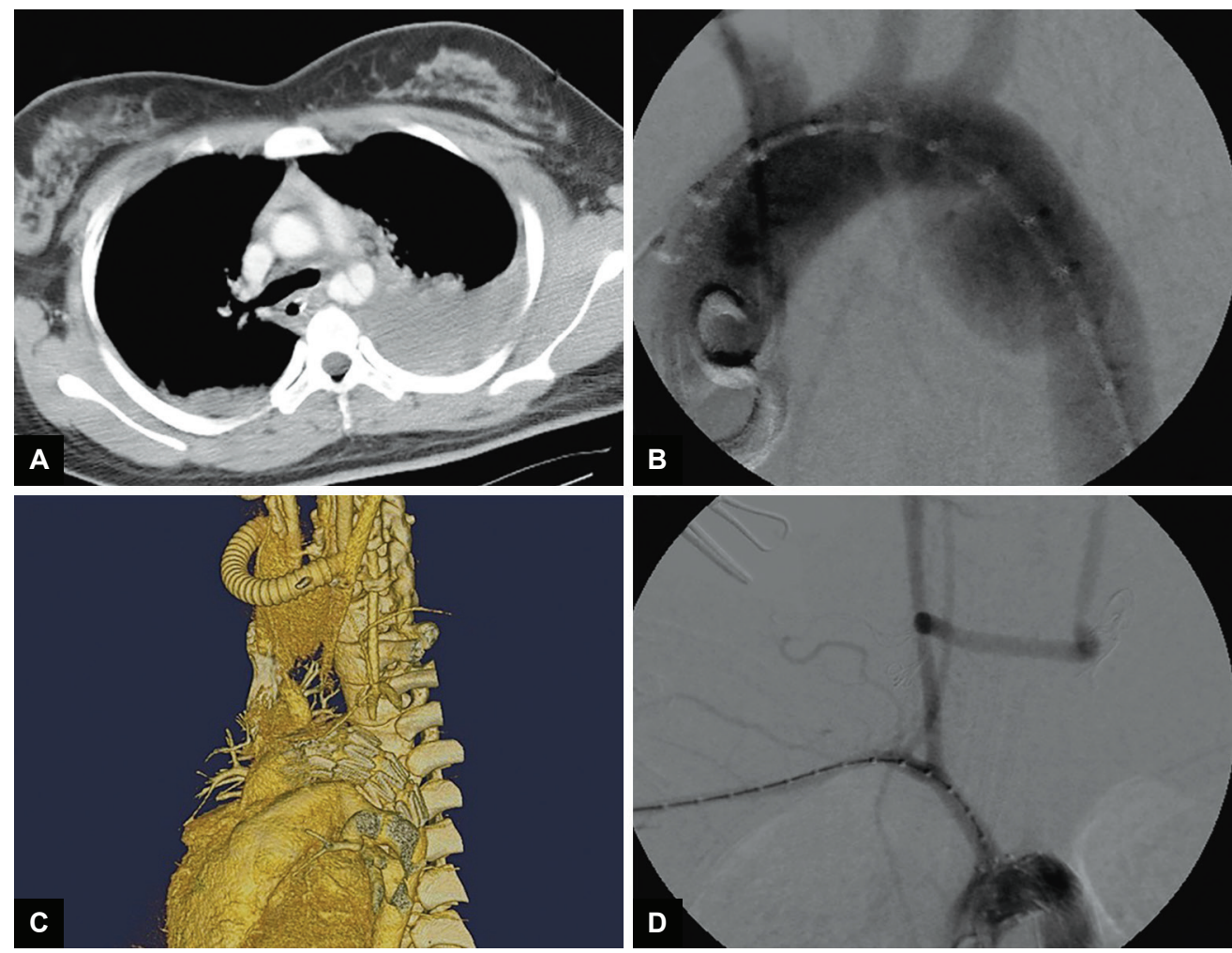

Figs $1 \mathrm{~A}$ to $\mathrm{D}$ : Preoperative, intraoperative, and postoperative image of blunt aortic injury. (A) Preoperative chest CT showing an intimal flap in descending aorta with left side hemothorax, compatible with a blunt aortic injury. (B) Aortogram before endovascular thoracic aortic repair: a bulging aneurysm over the distal aortic arch. (C) Reformed CT angiography demonstrated the carotid-tocarotid bypass and the aortic stent graft, which facilitated exclusion of the aortic lesion. (D) Completing aortogram demonstrated the relationship of the carotid-to-carotid bypass and the aortic stent graft

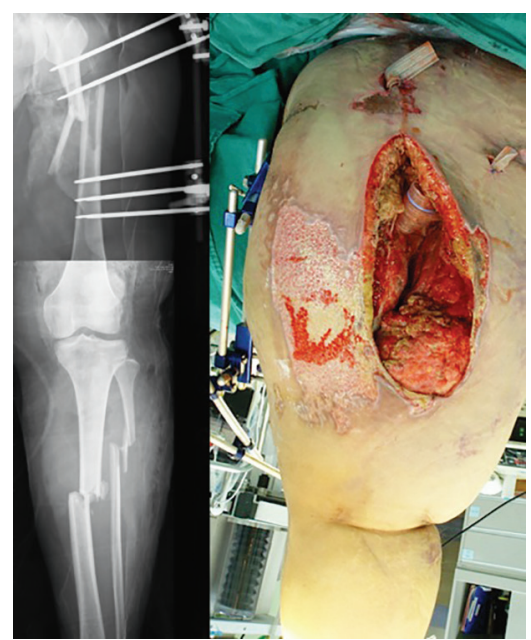

Fig. 2: Severe bony fracture and soft tissue injury in the same patient of Figure 1

death, interval between injury to ER, interval of trauma to orthopedic procedures, ER, ICU, and hospital stay. Patients treated with endovascular aortic repair had a tendency of shorter time interval from aortic intervention to orthopedic procedures in comparison with those who underwent open aortic surgery $(2.2 \pm 2.6$ vs $6.9 \pm 5.7$ days, $\mathrm{p}=0.03)$.

Given that endovascular repair of BTAI was a newly developed technique in comparison with open aortic
Table 4: Comparison between patients receiving orthopedic procedure with different aortic intervention

\begin{tabular}{llll}
\hline & $\begin{array}{l}\text { Traditional } \\
\text { aortic injury } \\
(n=13)\end{array}$ & $\begin{array}{l}\text { Endovascular } \\
\text { aortic repair } \\
(n=6)\end{array}$ & $\begin{array}{l}p \text {-value } \\
\text { Variables }\end{array}$ \\
\hline Gender: Male & 10 & 3 & 0.51 \\
Age & $32.0 \pm 19.7$ & $37.3 \pm 20.3$ & 0.63 \\
ISS & $29.1 \pm 6.5$ & $28.7 \pm 9.0$ & 0.92 \\
RTS & $7.0 \pm 1.0$ & $6.9 \pm 1.1$ & 0.80 \\
TRISS & $0.84 \pm 0.22$ & $0.86 \pm 0.17$ & 0.86 \\
Death & $0(0)$ & $0(0)$ & - \\
Ortho procedure from & $10.7 \pm 9.8$ & $7.7 \pm 5.4$ & 0.43 \\
injury (days) & & & \\
Ortho-op from aortic & $6.9 \pm 5.7$ & $2.2 \pm 2.6$ & $0.03^{* *}$ \\
surgery (days) & & & \\
Injury to ER (hr) & $3.8 \pm 6.0$ & $1.8 \pm 1.3$ & 0.27 \\
ER to diagnosis (hr) & $11.2 \pm 21.4$ & $9.5 \pm 17.3$ & 0.87 \\
ICU stay (days) & $4.5 \pm 3.2$ & $4.3 \pm 2.9$ & 0.86 \\
Hospital stay (days) & $36.5 \pm 26.0$ & $41.0 \pm 36.1$ & 0.81 \\
\hline
\end{tabular}

repair, and for the fact that in our study, endovascular repair was available only after 2006, we also compared all the indices mentioned above between patients who received open aortic repair and endovascular repair after 2006. We found out that that there were no differences in all demographics and injury severity, death, interval between injury to ER, interval of trauma to orthopedic 
Table 5: Comparison between patients receiving orthopedic procedure with different aortic interventions after 2006

\begin{tabular}{|c|c|c|c|}
\hline Variables & $\begin{array}{l}\text { Traditional } \\
\text { aortic injury } \\
(n=5)\end{array}$ & $\begin{array}{l}\text { Endovascular } \\
\text { aortic repair } \\
(n=6)\end{array}$ & $p$-value \\
\hline Gender: Male & 4 & 3 & 0.70 \\
\hline Age & $23.0 \pm 4.9$ & $37.3 \pm 20.3$ & 0.18 \\
\hline ISS & $24.4 \pm 5.9$ & $28.7 \pm 9.0$ & 0.41 \\
\hline RTS & $7.1 \pm 0.8$ & $6.89 \pm 1.07$ & 0.73 \\
\hline TRISS & $0.96 \pm 0.02$ & $0.86 \pm 0.17$ & 0.26 \\
\hline Death & $0(0)$ & $0(0)$ & - \\
\hline $\begin{array}{l}\text { Ortho procedure from } \\
\text { injury (days) }\end{array}$ & $9 \pm 5.5$ & $9.33 \pm 9.9$ & 0.95 \\
\hline $\begin{array}{l}\text { Ortho-op from aortic } \\
\text { surgery (days) }\end{array}$ & $6.4 \pm 5.2$ & $2.2 \pm 2.2$ & 0.19 \\
\hline Injury to ER (hr) & $6.3 \pm 8.9$ & $1.8 \pm 1.3$ & 0.37 \\
\hline ER to diagnosis (hr) & $10.6 \pm 18.7$ & $9.5 \pm 17.3$ & 0.93 \\
\hline ICU stay (days) & $3.6 \pm 2.2$ & $4.25 \pm 2.9$ & 0.71 \\
\hline Hospital stay (days) & $31.2 \pm 19.8$ & $41 \pm 36.11$ & 0.62 \\
\hline
\end{tabular}

procedures, ER, ICU, and hospital stay. It seems that there was no impact on the result of the two patient groups in terms of treatment plan of open aortic repair or endovascular repair (Table 5).

\section{Risk Factor Analysis}

In-hospital death occurred in 11 patients: 10 with conservative management of fracture (group I) and one in the operative fixation group (group II). Risk factors potentially affecting in-hospital mortality were further tested with the Cox proportional Hazard model (Table 6). Male and age had a positive impact (hazard ratio: 7.65, $\mathrm{p}=0.09$ and hazard ratio: $1.04, \mathrm{p}=0.05$ respectively) on mortality. Higher TRISS scale (hazard ratio: 0.02, $\mathrm{p}=0.004$ ) and endovascular aortic repair (hazard ratio: $0.26, \mathrm{p}=0.02$ ) also impacted on mortality. Operative fixation for fracture (Hazard ratio: 0.19, $\mathrm{p}=0.15$ ) had a negative impact on mortality. The survival curves for the nonoperative treatment, traditional open surgical repair, and endovascular aortic repair differed significantly $(\mathrm{p}=0.001 ;$ Graph 1).

\section{DISCUSSION}

Previous literature, which were associated with BTAI focused on the risk of sudden death and the relevant therapeutic options. According to an autopsy report, $34 \%$ of fatalities which resulted from a blunt mechanism had a thoracic aortic injury and of those patients with thoracic aortic injury, $80 \%$ died at the scene. ${ }^{9}$ Historically, these experiences led to emergent surgical approaches to aortic injuries after blunt trauma. Subsequent studies have suggested that some patients with major associated injuries, or even with no severe associated injuries or major comorbidities, can be safely
Table 6: Multiple Cox regression modeling in mortality

\begin{tabular}{lcccl}
\hline & $\begin{array}{l}\text { Parameter } \\
\text { estimated }\end{array}$ & $\begin{array}{l}\text { Standard } \\
\text { error }\end{array}$ & \multicolumn{2}{l}{ Hazard } \\
ratio & $p$-value \\
\hline Age & 0.04 & 0.02 & 1.04 & 0.05 \\
Male & 2.03 & 1.19 & 7.65 & 0.09 \\
TRISS & -3.71 & 1.29 & 0.02 & 0.004 \\
$\begin{array}{l}\text { Endovascular aortic } \\
\text { repair }\end{array}$ & -1.36 & 0.61 & 0.26 & 0.02 \\
$\begin{array}{l}\text { Receiving fixation for } \\
\text { fracture }\end{array}$ & -1.62 & 1.12 & 0.19 & 0.15 \\
\hline
\end{tabular}

Note: stepwise model selection

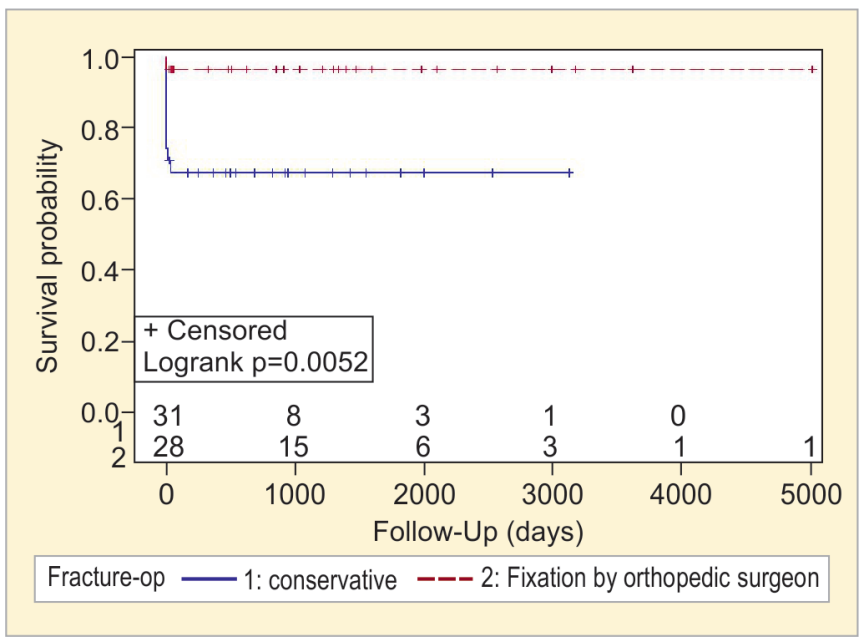

Graph 1: Survival examination groups by different therapeutic methods in blunt aortic trauma and fractures

managed with delayed repair, provided that blood pressure and contractility are adequately controlled. ${ }^{2,10-12}$ Delayed aortic repair has been associated with a significant risk-adjusted survival benefit as shown in the Second American Association for the Surgery of Trauma (AAST) trial, regardless of the presence or absence of major associated injuries. In the past decade, thoracic endovascular repair has revolutionized the therapy of descending aortic pathology. This therapeutic approach has been successfully applied for the treatment of BTAI. The prospective second AAST trial evaluated the impact of thoracic endovascular aortic repair (TEVAR) for BTAI across major trauma centers in the United States. The percentage of TEVAR use increased dramatically from 0 to $65 \%$ between the first AAST study in 1997 and the second in 2007. A comparative analysis in the second AAST study identified a $16 \%$ mortality rate after traditional open surgery vs $9 \%$ after endovascular repair $(\mathrm{p}=0.001){ }^{6}$

Most of the patients were with BTAI caused by high-energy impact from vehicle, exploration, machine crashing, and falling from heights. In contrast to abundant publications on epidemiology, anatomic distribution, prognostic factor, and therapeutic modality in BTAI, there is little discussion on the timing of treating 
coexisting injuries, such as orthopedics intervention. 7,13-15 Similarly, there is no relevant documentation on the impact of different aortic surgical options on the other trauma care providers, which may prevent the effective communication among the traumatic team mates. About $67 \%(59 / 88)$ of our patients with blunt aortic injury had complications with long bone, spine, scapula, ribs, and other bone fractures. Among those BTAI patients with fractures, $47.5 \%(28 / 59)$ required operative treatment for the factures to facilitate hemostasis or functional restoration. In contrast to overt diagnosis of bone fractures from limb deformities or tenderness, $44.1 \%$ of the aortic lesions lacked relevant symptoms or signs, and thus could only be found with screening contrasted CT. Furthermore, for at least $6.8 \%(4 / 59)$ of the patients with both bone fracture and BTAI, the aortic injuries were established after the orthopedic procedures (Table 1).

This study tried to determine the orthopedic therapeutic options in a scenario with coexisting aortic injuries. The fractures were treated conservatively in 31 patients (group I) and were treated operatively in 28 patients (group II). Group I (conservative management of fracture) had a higher mortality and shorter diagnosis of aortic lesion ( $5.7 \pm 17.7$ vs $7.6 \pm 17.5$ hours), though there were no differences in aortic interventions between groups I and II $(p=0.51)$. These findings may imply that there is no need to postpone orthopedics procedures due to coexisting BTAI. Prompt decision of fixation of trauma may be the choice in case of comorbid of fractures and BTAI. Coexisting lesions in patients with blunt aortic trauma, including pelvic, scapula, and extremities fractures have been previously reported. ${ }^{7,8,13,14}$ One Spanish retrospective study for developing a scoring system for early detection of traumatic aortic injury revealed some associated orthopedic lesions. ${ }^{8}$ In their comparison of coexisting lesions between patients with aortic injury and patients without aortic injury, they showed a similar prevalence of long bone fracture in BTAI as in our study, but comparably higher pelvic fracture, higher scapula fracture, and higher spinal fracture. However, the timing of orthopedic procedures and the impact of different aortic interventions in this scenario have never been previously reported. In our experience, patients treated with endovascular aortic repair had a trend of shorter orthopedic procedure after aortic intervention in comparison with those having open aortic surgery $(2.2 \pm 2.6$ vs $6.9 \pm 5.7$ days, $\mathrm{p}=0.03)$. Nonetheless, the significance was erased when we further examined the comparison between patients receiving the two different treatment methods after 2006. Thus, the rapid diagnoses of endovascular repair of BTAI in patients with orthopedic procedures may be attributed partially to the improvement of traumatology and experience in the relevant disease, since all endovascular aortic repairs were performed after 2006 when the aortic stents became available in our institute. Although the endovascular aortic repair did not shorten ICU and hospital stay, it may be associated with a hastening of orthopedic procedures after stabilizing the aortic lesion (Tables 4 and 5). Ignoring the possibility of blunt aortic injury in orthopedic procedures not only increases surgical risk, but also legal arguments, which emerged in four cases in this study. Two of these cases were pelvic fractures in critical condition requiring immediate fixation for hemostasis on arrival to ER. One was a patient with left shoulder dislocation, left radio-ulnar fracture, and right femoral shaft fracture in a pedestrian-to-vehicle crash. The last one was a victim of type II open tibial fracture in a pedestrian-to-vehicle crash with minimal evidence of chest trauma. The aortic injuries in those four patients were disclosed by chest CT indicating progressive mediastinum widening and hemodynamic changes (Table 3).

Multiple Cox regression analysis for those patients of aortic injury with concomitant fractures showed that age and male gender had a positive impact, while higher TRISS score, use of endovascular aortic repair, and receiving orthopedic procedures had a negative impact on mortality (Table 6). Those findings suggest that the benefit of endovascular aortic repair on aortic morphologic lesions is that these patients can be stabilized from major trauma in order to receive scheduled orthopedic procedures, thus possibly leading to better prognoses.

A small retrospective characteristic of heterogeneity of the cohort is the major limitation of this investigation. With such a limitation, we attempted to identify variables associated with a poor prognosis and the influence of the different therapeutic options and to provide useful information for the communication between trauma team mates.

\section{CONCLUSION}

Patients with multiple traumas including BTAI had better outcome when they could be treated aortic lesions operatively. Patients treated by endovascular aortic repair tended to receive faster orthopedic corrections following aortic surgery, compared with patients with open aortic surgery. At last, BTAI tended to be missed by initial survey in multiple trauma patients with more complex and severe fractures.

\section{REFERENCES}

1. Fabian TC, Richardson JD, Croce MA, Smith JS Jr, Rodman G Jr, Kearney PA, Flynn W, Ney AL, Cone JB, Luchette FA, et al. Prospective study of blunt aortic injury: Multicenter Trial of the American Association for the Surgery of Trauma. J Trauma 1997 Mar;42(3):374-380. 
2. Hemmila MR, Arbabi S, Rowe SA, Brandt MM, Wang SC, Taheri PA, Wahl WL. Delayed repair for blunt thoracic aortic injury: is it really equivalent to early repair? J Trauma 2004 Jan;56(1):13-23.

3. Rheaume P, Chen J, Casey P. Open vs endovascular repair of blunt traumatic thoracic aortic injuries. J Vasc Surg 2010 Mar;51(3):763-769.

4. Forman MJ, Mirvis SE, Hollander DS. Blunt thoracic aortic injuries: CT characterisation and treatment outcomes of minor injury. Eur Radiol 2013 Nov;23(11):2988-2995.

5. Caffarelli AD, Mallidi HR, Maggio PM, Spain DA, Miller DC, Mitchell RS. Early outcomes of deliberate nonoperative management for blunt thoracic aortic injury in trauma. J Thorac Cardiovasc Surg 2010 Sep;140(3):598-605.

6. Demetriades D, Velmahos GC, Scalea TM, Jurkovich GJ, Karmy-Jones R, Teixeira PG, Hemmila MR, O'Connor JV, McKenney MO, Moore FO, et al. Diagnosis and treatment of blunt thoracic aortic injuries: changing perspectives. J Trauma 2008 Jun;64(6):1415-1418.

7. InabaK,KirkpatrickAW,FinkelsteinJ,MurphyJ,BrennemanFD, Boulanger BR, Girotti M. Blunt abdominal aortic trauma in association with thoracolumbar spine fractures. Injury 2001 Apr;32(3):201-207.

8. Mosquera VX, Marini M, Muniz J, Asorey-Veiga V, Adrio-Nazar B, Boix R, Lopez-Perez JM, Pradas-Montilla G,
Cuenca JJ. Traumatic aortic injury score (TRAINS): an easy and simple score for early detection of traumatic aortic injuries in major trauma patients with associated blunt chest trauma. Intensive Care Med 2012 Sep;38(9):1487-1496.

9. Prijon T, Ermenc B. Classification of blunt aortic injuries a new systematic overview of aortic trauma. Forensic Sci Int 2010 Feb;195(1-3):6-9.

10. Neschis DG, Scalea TM, Flinn WR, Griffith BP: Blunt aortic injury. N Engl J Med 2008 Oct;359(16):1708-1716.

11. Lebl DR, Dicker RA, Spain DA, Brundage SI. Dramatic shift in the primary management of traumatic thoracic aortic rupture. Arch Surg 2006 Feb;141(2):177-180.

12. Hilgenberg AD, Logan DL, Akins CW, Buckley MJ, Daggett WM, Vlahakes GJ, Torchiana DF. Blunt injuries of the thoracic aorta. Ann Thorac Surg 1992 Feb;53(2): 233-238.

13. Stambough JL, Ferree BA, Fowl RJ. Aortic injuries in thoracolumbar spine fracture-dislocations: report of three cases. J Orthop Trauma 1989 Sep;3(3):245-249.

14. Brown CV, Velmahos G, Wang D, Kennedy S, Demetriades D, Rhee P. Association of scapular fractures and blunt thoracic aortic injury: fact or fiction? Am Surg 2005 Jan;71(1):54-57.

15. de Mestral C, Dueck AD, Gomez D, Haas B, Nathens AB. Associated injuries, management, and outcomes of blunt abdominal aortic injury. J Vasc Surg 2012 Sep;56(3):656-660. 